Joachim Englisch

\title{
Wettbewerbsgleichheit im grenzüberschreitenden Handel
} mit Schlussfolgerungen für indirekte Steuern

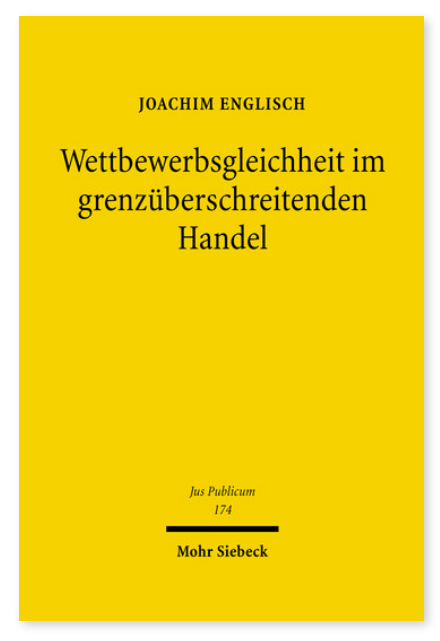

2008. XXIII, 892 Seiten. JusPubl 174

ISBN 978-3-16-151255-1

DOI 10.1628/978-3-16-151255-1

eBook PDF 189,00€

ISBN 978-3-16-149415-4

Leinen $189,00 €$
Infolge des stetigen Abbaus zolltarifärer und sonstiger Marktzutrittsschranken verlieren spezifisch an den Grenzübertritt anknüpfende Hemmnisse für den grenzüberschreitenden Handel zunehmend an Bedeutung. In den Fokus rücken stattdessen solche Vorgaben, die den internationalen Güteraustausch auch hinsichtlich der allgemeinen rechtlichen Rahmenbedingungen vor Wettbewerbsnachteilen schützen sollen. Vom deutschen Gesetzgeber sind insofern vor allem die Bestimmungen des EG-Vertrages sowie des Welthandelsrechts zu beachten. Joachim Englisch analysiert die einschlägigen Diskriminierungsverbote und kontrastiert sie mit den Anforderungen des Grundgesetzes. Er untersucht zunächst die rechtsdogmatischen Strukturen gleichheitsrechtlicher Direktiven und bettet sie in die Lehre vom Rechtsprinzip ein. Von besonderem Interesse sind sodann die wechselseitigen Verschränkungen im Mehrebenensystem und die verbleibenden Gestaltungsspielräume des nationalen Gesetzgebers bei der Verfolgung kollidierender Ziele. Neben dem Gebot folgerichtiger Wertung kommt hier dem Verhältnismäßigkeitsgrundsatz auch gleichheitsrechtlich eine zentrale, obschon je nach dem Entwicklungsstand der Rechtsordnung abgestufte Rolle zu. Der Autor rundet die Untersuchung mit Schlussfolgerungen zur Anwendung der gewonnenen Erkenntnisse auf dem Gebiet der indirekten Steuern ab. Im Vordergrund stehen dabei die Bedeutung des Leistungsfähigkeitsprinzips, versteckt diskriminierende Steuersysteme sowie die internationale Doppelbesteuerung.

Das Buch wurde mit dem Albert-Hensel-Preis 2007 ausgezeichnet.

Joachim Englisch Studium der Rechtswissenschaften und der Betriebswirtschaftslehre an den Universitäten in Saarbrücken, Salamanca (Spanien) und Köln; 1998 Erste juristische Staatsprüfung; zunächst wissenschaftlicher Mitarbeiter, danach wissenschaftlicher Assistent am Institut für Steuerrecht der Universität zu Köln; 2004 Promotion; 2007 Habilitation; 2008 Inhaber des Lehrstuhls für Steuerrecht, Finanzrecht und Öffentliches Recht der Universität Augsburg; seit 2010 Inhaber des Lehrstuhls für Öffentliches Recht und Steuerrecht an der Universität Münster.

Jetzt bestellen:

https://mohrsiebeck.com/buch/wettbewerbsgleichheit-im-grenzueberschreitenden-handel-9783161512551?no_cache=1 order@mohrsiebeck.com

Telefon: $+49(0) 7071-923-17$

Telefax: +49(0)7071-51104 